\title{
Single center experience of laparoscopic hepatectomy: the comparison of perioperative outcomes between early and late period
}

\author{
Seung Hyeon Son, Hong Jin Kim, Sung Su Yun, Dong Shik Lee, and Dong Hyeon Lee \\ Department of Surgery, Yeungnam University College of Medicine, Daegu, Korea
}

\begin{abstract}
Backgrounds/Aims: The aim of this study is to clarify the safety and feasibility of laparoscopic hepatectomy, through comparing the early and late periods of perioperative outcomes. Methods: We retrospectively analyzed 138 patients who underwent laparoscopic hepatectomy from January 2003 to June 2011, at Yeungnam University Hospital. We divided the total patients to early period (from January 2003 to February 2007, n=49) and late period (from March 2007 to June 2011, n=89) groups and compared the perioperative outcomes including the mean operation time, intraoperative blood loss, postoperative hospital stay, intensive care unit (ICU) stay, and duration of liver function test (LFT) normalization. Results: The mean operation time was 308 minutes (range: 140-510) in the early group and 193 minutes (range: $40-350)$ in the late period group $(p<0.001)$. The mean intraoperative blood loss was $171 \mathrm{ml}($ range: $50-1,200)$ in the early and $44 \mathrm{ml}$ (range: $0-400)$ in the late group $(p=0.005)$. The postoperative hospital stay was 9.7 days (range: $4-31$ ) in the early and 6.8 days (range: $2-9)$ in the late period $(p<0.001)$. The ICU stay hour was 21.6 hours (range: $0-120)$ in the early and 2.8 hour (range: $0-24)$ in the late period $(p<0.001)$. The duration of LFT normalization was 5.7 days (range: $0-39)$ in the early and 2.1 days (range: $0-20)$ in the late period $(p=0.003)$. The perioperative outcomes in the late period were better than the early period, which showed a statistically significant difference. Conclusions: Laparoscopic hepatectomy is feasible and can be safely performed in selected patients but requires a long experience in open liver resection and mastery of laparoscopic surgical skills. (Korean J Hepatobiliary Pancreat Surg 2012;16:7-12)
\end{abstract}

Key Words: Laparoscopy; Hepatectomy; Outcome

\section{INTRODUCTION}

Laparoscopy has become an integral component of surgical procedures because it offers a shorter postoperative course, better cosmetics, and less pain than the conventional methods. ${ }^{1,2}$ The progressive growth in the popularity of laparoscopic surgery and the widespread acceptance of laparoscopic cholecystectomy has encouraged surgeons to apply laparoscopic methods to the management of number of hepatic tumors. ${ }^{3}$ Unfortunately, application of laparoscopy to liver resection has been slowed due to technical difficulties. The difficulties include maintaining hemostasis at the transection plane, controlling hemorrhage, and exploring deeper regions of the liver. ${ }^{3}$ Despite these initial obstacles, Gagner and Rheault ${ }^{4}$ reported first two cases of non-anatomical laparoscopic liver resection in 1992. The first laparoscopic anatomical resection (left lateral segmentectomy) was performed by Azagra et al. in $1996 .{ }^{5}$ Over the past 15 years, liver resections were introduced to clinical practice based on case series. It demonstrated the usual benefits of minimally invasive procedures, without loss of efficacy of the operations. However, the feasibility of laparoscopic liver surgery was better acknowledged following a prospective study by Cherqui et al. ${ }^{6}$ Recently, with improvements of surgical technology, devices and further accumulated experiences, even major hepatectomy has been attempted by laparoscopic method.

The aim of this study is to clarify the safety and feasibility of laparoscopic liver resection, via a comparison between the early and late period perioperative outcomes.

Received: December 21, 2011; Revised: January 10, 2012; Accepted: January 20, 2012

Corresponding author: Hong Jin Kim

Department of Surgery, Yeungnam University College of Medicine, Daemyeong-5 dong, Nam-gu, Daegu 705-717, Korea

Tel: +82-53-620-3585, Fax: +82-53-624-1213, E-mail: hjkim@med.yu.ac.kr 


\section{METHODS}

\section{Patients}

One hundred forty two patients who underwent laparoscopic liver resections from January 2003 to June 2011 at Yeungnam University Hospital were collected for this study. Among them, 4 patients undergoing an open conversion were excluded. Finally, 138 patients were included for the purpose of this study. Initial diagnosis was made by laboratory examinations and radiologic findings, including abdominal ultrasonography (USG), computed tomography (CT) and magnetic resonance imaging (MRI).

Laboratory examinations were included such as, complete blood count, albumin, bilirubin, liver enzyme, prothrombin time (PT), activated partial thromboplastin time (aPTT), and Indocyanine Green (ICG) R15. The number of study patients in the early period (from January 2003 to February 2007) and the late period groups (March 2007 to June 2011) were 49 and 89 , respectively.

\section{Surgical techniques}

All procedures were performed under the general anesthesia with endotracheal tube insertion, after obtaining informed consent. All resections were performed with supine position. Pneumoperitoneum was established by open technique, and intra-abdominal carbon dioxide gas pressure was set at $12 \mathrm{mmHg}$ to prevent gas embolism. A 10 $\mathrm{mm} 0^{\circ}$ flexible laparoscope was placed through the umbilical port for abdominal exploration. Additional 5 or 12 mm-sized trocars were placed at particular sites, depending on the location of the liver lesion. In case of major hepatectomy, the control of portal pedicles was usually performed before parenchyma dissection of the liver to identify parenchyma dissection line and to reduce bleeding. Arterial branches were clipped with hemolock clips and then divided. The portal branch was divided with hemolock clips or an endoscopic linear stapler. The common bile duct was dissected as high as possible, without any duct section injury. The hilar plate was divided and sutured above the biliary convergence after the completion of parenchyma dissection or before it. The hepatic vein was dissected free but not divided before parenchymal division. Hepatic transection was initiated according to the line of demarcation, visualized on Glisson's capsule, directed to the axis of the inferior vena cava. In the case of non-anatomical resection, the resection line was marked at the liver surface by electrocautery, following ultrasonographic examination to locate the tumor and the supply vessels, demonstration of satellite nodules, and demarcation of an adequate tumor-free margin. The capsule was divided by the use of Harmonic scalpel ${ }^{\circledR}$ or Ligasure ${ }^{\circledR}$ and deep within the liver parenchyma and a Cavitron ultrasonic aspirator (CUSA) was used to define the vascular structures. Minor vessels and bile ducts were divided using the Harmonic scalpel ${ }^{\circledR}$, diathermy, and clips. Larger vessels were divided with an endoscopic linear stapler or hemolock clips. During the operation, central venous pressure (CVP) was maintained, with $3 \mathrm{cmH}_{2} \mathrm{O}$ or less, if possible.

\section{Statistical analysis}

For comparing both period groups of laparoscopic liver resection, variables included preoperative laboratory examination such as, complete blood count, albumin, bilirubin, liver enzyme, PT, aPTT, ICG R15, and mean operation time, intraoperative blood loss, postoperative hospital days, intensive care unit (ICU) stay days, and finally, the duration of liver function test (LFT) normalization and postoperative complications.

The data are presented as a median (range) or a number (percentage). We used Fisher's exact test to compare proportions between the groups. For comparison of continuous variables, the Mann-Whitney test was used. A $p<$ 0.05 was considered statistically significant. We used analysis software SPSS v.12.0.

\section{RESULTS}

\section{Patient characteristics}

The laparoscopic liver resections of the early and late period groups were 49 patients and 89 patients, respectively. The sex and preoperative laboratory findings were similar in both periods. The older age $(p=0.09)$ and co-morbid disease $(p=0.06)$ were more common in the late period than that of the early period without statistically difference (Table 1). Liver disease was benign in 35 and malignant in 103 cases. Malignant disease was more common in the late period (early: $37.2 \%$ vs. late: $73.8 \%$ ). The most common benign disease was intrahepatic bile duct stone $(54.3 \%)$ in both periods. Hepatocellular carcinoma 
Table 1. Clinical and laboratory findings between the early and late periods

\begin{tabular}{|c|c|c|c|}
\hline & Early period $(n=49)$ & Late period $(\mathrm{n}=89)$ & $p$-value \\
\hline Sex (male/female) & $22 / 27$ & $63 / 26$ & 0.73 \\
\hline Age (year) : mean (range) & $55.9(41-81)$ & $60.7(39-78)$ & 0.09 \\
\hline Co-morbidity & $15(30 \%)$ & $51(57 \%)$ & 0.06 \\
\hline Cardiovascular disease & $7(47 \%)$ & $26(51 \%)$ & \\
\hline Diabetes mellitus & $3(20 \%)$ & $10(20 \%)$ & \\
\hline Viral hepatitis $\mathrm{B}$ or $\mathrm{C}$ & $5(33 \%)$ & $15(29 \%)$ & \\
\hline \multicolumn{4}{|l|}{ Preoperative laboratory findings (mean (range)) } \\
\hline Hemoglobin $(\mathrm{g} / \mathrm{dl})$ & $12.2(10-16)$ & $13.1(11-15)$ & 0.83 \\
\hline Platelet $\left(10^{3} / \mu 1\right)$ & $144(140-490)$ & $132(120-443)$ & 0.96 \\
\hline Serum total bilirubin $(\mathrm{mg} / \mathrm{dl})$ & $0.77(0.3-1.5)$ & $0.9(0.1-1.6)$ & 0.99 \\
\hline Serum albumin $(\mathrm{g} / \mathrm{dl})$ & $3.9(3-5)$ & $4.0(3.1-4.8)$ & 0.56 \\
\hline Prothrombin time $(\%)$ & $85(81-111)$ & $89(84-118)$ & 0.44 \\
\hline Activated partial thromboplastin time (sec) & $32(25-40)$ & $35(22-41)$ & 0.74 \\
\hline ICG R15 (\%) & $9.0(4-14)$ & $9.2(5.2-18)$ & 0.99 \\
\hline
\end{tabular}

ICG R15, indocyanine green retention test at 15 minutes

Table 2. Clinicopathological features of liver lesions in the early and late periods

\begin{tabular}{|c|c|c|c|}
\hline & Early period $(n=49)$ & Late period $(n=89)$ & $p$-value \\
\hline Benign & $22(45 \%)$ & $13(15 \%)$ & 0.08 \\
\hline Hemangioma & $2(9 \%)$ & $1(7.5 \%)$ & \\
\hline Adenoma & $1(4.5 \%)$ & $0(0 \%)$ & \\
\hline Focal nodular hyperplasia & $1(4.5 \%)$ & $1(7.5 \%)$ & \\
\hline Intrahepatic duct stone & $11(50 \%)$ & $8(61 \%)$ & \\
\hline Cyst & $7(32 \%)$ & $3(24 \%)$ & \\
\hline Malignancy & $27(55 \%)$ & $76(85 \%)$ & 0.09 \\
\hline Hepatocellular carcinoma & $22(81 \%)$ & $52(68 \%)$ & \\
\hline Intrahepatic cholangiocarcinoma & $2(7 \%)$ & $4(6 \%)$ & \\
\hline Metastasis from colon cancer & $3(12 \%)$ & $20(26 \%)$ & \\
\hline Mean tumor size $(\mathrm{cm})$, range & $3.5(1.2-4)$ & $3.0(1-4.1)$ & 0.88 \\
\hline Mean number of tumor (range) & $1.2(1-2)$ & $1.2(1 / 2)$ & $>0.99$ \\
\hline \multicolumn{4}{|l|}{ Tumor location } \\
\hline Segment 5 or 6 & $29(59 \%)$ & $46(51 \%)$ & $>0.99$ \\
\hline Left lateral section & $15(30 \%)$ & $30(34 \%)$ & 0.65 \\
\hline Right posterior section & $5(11 \%)$ & $13(15 \%)$ & 0.43 \\
\hline
\end{tabular}

(71.8\%) was the most common malignant disease in both periods (Table 2). Tumor size, number and locations were similar in both periods.

\section{Types of laparoscopic liver resection}

The operation type was categorized into minor resection (wedge resection, segmentectomy, sectionectomy) and major resection (right and left hemihepatectomy. In the early and late periods, the percentage of wedge resection was $27 \%$ and $33 \%(p=0.27)$; segmentectomy was $10 \%$ and $20 \%$ ( $p=0.09$ ), sectionectomy was $29 \%$ and $25 \%$ $(p=0.50)$; left hemihepatectomy was $12 \%$ and $9 \%$ ( $p=$ $0.82)$; right hemihepatectomy was $22 \%$ and $13 \%(p=0.74)$; and the percentage of major liver resection was $34 \%$ and
$22 \%(p=0.99)$, respectively. There was no significant difference in the operation type between both groups (Table 3).

\section{Perioperative outcomes}

The overall mean operation time was 308 minutes (range: 140-510) in the early period and 193 minutes (range: 40-350) in the late period $(p<0.001)$ (Table 4$)$. In each type of the operation, mean operation time of wedge resection or segmentectomy was 130 minutes and 115 minutes $(p=0.005)$, respectively, sectionectomy was 252 minutes and 233 minutes $(p=0.004)$, left hemihepatectomy was 330 minutes and 318 minutes $(p=0.004)$, and right hemihepatectomy was 360 and 330 minutes ( $p=$ 
Table 3. Extents of laparoscopic liver resections between the early and late periods

\begin{tabular}{lrrr}
\hline & Early period $(\mathrm{n}=49)$ & Late period $(\mathrm{n}=89)$ & $p$-value \\
\hline Minor liver resection & $39 / 49(66 \%)$ & $71 / 89(78 \%)$ & 0.75 \\
Wedge resection & $16(27 \%)$ & $30(33 \%)$ & 0.27 \\
Segmentectomy & $6(10 \%)$ & $18(20 \%)$ & 0.09 \\
Sectionectomy & $17(29 \%)$ & $23(25 \%)$ & 0.5 \\
Major liver resection & $10 / 49(34 \%)$ & $18 / 89(22 \%)$ & $>0.99$ \\
Left hemihepatectomy & $7(12 \%)$ & $8(9 \%)$ & 0.82 \\
Right hemihepatectomy & $3(22 \%)$ & $10(13 \%)$ & 0.74 \\
\hline
\end{tabular}

Table 4. The comparison of intraoperative and postoperative outcomes between the early and late periods (mean values and range)

\begin{tabular}{lcrr}
\hline & Early period & Late period & $p$-value \\
\hline Overall operation time (minute) & $308(140-510)$ & $193(40-350)$ & $<0.001$ \\
Blood loss (ml) & $171(50-1,200)$ & $44(50-400)$ & 0.005 \\
Postoperative hospital stay (days) & $9.7(4-31)$ & $6.8(2-9)$ & $<0.001$ \\
ICU stay (hours) & $21.6(0-120)$ & $4.8(0-24)$ & $<0.001$ \\
Duration of LFT normalization (days) & $5.7(0-39)$ & $2.1(0-20)$ & 0.003 \\
\hline
\end{tabular}

LFT, liver function test

Table 5. The comparison of operation time between the early and late periods

\begin{tabular}{lccc}
\hline & $\begin{array}{c}\text { Early } \\
\text { period } \\
\text { (minutes) }\end{array}$ & $\begin{array}{c}\text { Late } \\
\text { period } \\
\text { (minutes) }\end{array}$ & $p$-value \\
\hline $\begin{array}{l}\text { Wedge resection or } \\
\text { segmentectomy }\end{array}$ & 130 & 115 & 0.005 \\
Sectionectomy & 252 & 233 & 0.004 \\
Left hemihepatectomy & 330 & 318 & 0.004 \\
Right hemihepatectomy & 360 & 330 & 0.005 \\
\hline
\end{tabular}

0.005), in early period and late period, respectively (Table 5). The mean intraoperative blood loss was $171 \mathrm{ml}$ (range: 50-1,200) in the early and $44 \mathrm{ml}$ (range: 0-400) in the late $(p=0.005)$. In the late period, the mean operation time and intraoperative blood loss were significantly less than the early period (Table 3 ). The postoperative hospital stay was 9.7 days (range: 4-31) in the early and 6.8 days (range: $2-9)$ in the late period $(p<0.001)$. The ICU stay hour was 21.6 hours (range: $0-120$ ) in the early and 2.8 hours (range: $0-24)$ in the late period $(p<0.001)$. The duration to LFT normalization was 5.7 days (range: 0-39) in the early and 2.1 days (range: $0-20$ ) in the late period ( $p=0.003$ ). The intraoperative and postoperative outcomes in the late period were better than the early and it showed a statistical difference (Tables 4,5 ).

\section{Postoperative complications}

The overall postoperative complication was $16 \%$ and $3 \%$ in the early and the late periods, respectively, with statistical difference (Table 6). Further, surgical and medical complications were significantly more common in the early period than in the late period. Wound infection and pulmonary complication were common in both periods. Postoperative bile leakage and renal insufficiency were not documented in either period. There was no perioperative death in both periods.

\section{DISCUSSION}

The widespread success of laparoscopic cholecystectomy has opened new frontiers and led to the application of laparoscopic techniques, to a wide variety of more complex surgical procedures. However, laparoscopic liver surgery has been slow to develop because of perceived technical difficulties. ${ }^{7-10}$ Since the first laparoscopic liver resection was performed in $1992,{ }^{4}$ laparoscopic liver resection has been widely discussed with debate focusing on the feasibility, safety, oncological efficiency and surgical indications. ${ }^{11-14}$ The first two issues were addressed early in the first part of this decade ${ }^{15-17}$ and oncological efficiency has been recently demonstrated. ${ }^{18}$

The gradual trend toward bloodless surgery in tradi- 
Table 6. Postoperative complications

\begin{tabular}{lccc}
\hline & Early period $(\mathrm{n}=49)$ & Late period $(\mathrm{n}=89)$ & $p$-value \\
\hline Surgical complications & $4 / 49(8 \%)$ & $2 / 89(2 \%)$ & 0.005 \\
Wound infection & 3 & 2 & \\
Bleeding & 1 & 0 & 0.002 \\
Bile leakage & 0 & 0 & \\
Medical complications & $4 / 49(8 \%)$ & 0 & \\
Heart failure & 2 & 0 & 0.004 \\
Renal failure & 0 & $3 / 89(3 \%)$ & $0.89)$ \\
Pulmonary complication & 2 & $(1 \%)$ & \\
Total & $8 / 49(16 \%)$ & & \\
\hline
\end{tabular}

tional techniques of hepatic resection, greater experience with laparoscopic surgery, with improvements in video equipment, laparoscopic instrumentation, and surgical skills have led hepatobiliary surgeons to attempt laparoscopic management in the application of various hepatic lesions. Their results were not as bad as expected- no worse than those of open surgery. ${ }^{1,19-23}$

In malignant disease, achievement of a tumor-free margin, while resecting a malignant neoplasm, is of importance due to the limits of the laparoscopic liver resection. Some studies reported the same rate of negative surgical margins after laparoscopic and open liver resections. An European multicenter study showed that there was no evidence that the use of a laparoscopic technique increases the risk of local recurrence or port-site metastases. ${ }^{8,10}$ Further, using intraoperative laparoscopic ultrasound helps to demarcate the line of resections and compensates for the loss of tactile sensation.

According to some studies, mortality of laparoscopic surgeries are almost the same when comparing with large case series of open major liver resection, and thus the oncologic goals like complete resections are maintained. ${ }^{24-26}$ In our study, in the late period, the portion of old age, patient with comorbidity, and malignant tumor were more than in the early period. It is due to the widening of indication of laparoscopic liver resection in addition to the improvements of the surgical techniques and devices.

One of the main concerns during hepatectomy is minimizing blood loss and avoidance of blood transfusion. ${ }^{27,28}$ In our experience, laparoscopic surgery may provide better visualization of deep vascular structures and more precise and accurate surgery. To avoid injury to the hepatic veins during manipulation of secondary hilar structures, caution should be paid and the hepatic veins should be transected in the parenchyma using clips or endoscopic linear stapler. In the early stage of laparoscopic hepatectomy, bleeding during parenchymal transection, due to a lack of effective devices, is another important cause of blood loss. However, there are many advancements made recently in the devices for dividing the parenchyma, including an ultrasonic scalpel, microwave tissue coagulator, Ligasure ${ }^{\circledR}$, water jet dissector, CUSA, and argon beam coagulator. According to our experience, using a LigaSure $^{(\mathbb{R}}$ and Harmonic scalpel ${ }^{\mathbb{R}}$ to transect the liver, it facilitates good hemostasis, less effusion, clear anatomy, and minor damage to liver function. The mean blood loss was $171 \mathrm{ml}$ in the early and $44 \mathrm{ml}$ in the late period. In the late period, with the improved instruments and experience, intraoperative bleeding was less than in the early period.

There are now numerous excellent devices for dividing the parenchyma, including ultrasonic scalpel, microwave tissue coagulator, water jet dissector, LigaSure ${ }^{\circledR}$, CUSA, argon beam coagulator, and TissueLink. Furthermore, accumulated operation skill and experience, is perhaps the biggest component. ${ }^{10,29}$ In our study, operation time was shortened in the late period (193 minutes) compared with those in the early period (308 minutes). And postoperative hospital days (early 9.7 days, late 6.8 days), postoperative ICU stay (early 21.6 hours vs. late 4.8 hours) and duration for LFT normalization (early 5.7 days vs. late 2.1 days) were also shortened in the late period than in the early period. Postoperative complication was less in the late period $(3 \%)$ than in the early period $(16 \%)$. Further, postoperative death was not seen in both periods. Therefore, laparoscopic liver resection has many benefits than disadvantages. In addition, with accumulated experience and development of better devices, laparoscopic liver re- 
section can be performed safely and further indications can be made.

In conclusion, laparoscopic liver surgery can be safely performed but requires a long experience in open liver resection and mastery of laparoscopic surgical skills. It can be performed with excellent results in selected patients, even when major hepatectomy is required. It has benefits including less pain, minimal scar, less hospital and ICU stay. We expect laparoscopic liver resection to develop more in the future, as a promising new surgical method, which significantly improves patients' quality of life.

\section{ACKNOWLEDGEMENTS}

This research was supported by grant of Yeungnam University Medical Center (2010).

\section{REFERENCES}

1. Descottes B, Lachachi F, Sodji M, et al. Early experience with laparoscopic approach for solid liver tumors: initial 16 cases. Ann Surg 2000;232:641-645.

2. Min SK, Han HS, Kim SW, Park YH, Lee HO, Lee JH. Initial experiences with laparoscopy-assisted and total laparoscopy for anatomical liver resection: a preliminary study. J Korean Med Sci 2006;21:69-74.

3. Kaneko H. Laparoscopic hepatectomy: indications and outcomes. J Hepatobiliary Pancreat Surg 2005;12:438-443.

4. Gagner M, Rheault MJD. Laparoscopic partial hepatectomy for liver tumor. Surg Endosc 1992;6:97-98.

5. Azagra JS, Goergen M, Gilbart E, Jacobs D. Laparoscopic anatomical (hepatic) left lateral segmentectomy-technical aspects. Surg Endosc 1996;10:758-761.

6. Cherqui D, Husson E, Hammoud R, et al. Laparoscopic liver resections: a feasibility study in 30 patients. Ann Surg 2000;232: 753-762.

7. Croce E, Azzola M, Russo R, Golia M, Angelini S, Olmi S. Laparoscopic liver tumour resection with the argon beam. Endosc Surg Allied Technol 1994;2:186-188.

8. Gigot JF, Glineur D, Santiago Azagra J, et al; Hepatobiliary and Pancreatic Section of the Royal Belgian Society of Surgery and the Belgian Group for Endoscopic Surgery. Laparoscopic liver resection for malignant liver tumors: preliminary results of a multicenter European study. Ann Surg 2002;236:90-97.

9. Morino M, Morra I, Rosso E, Miglietta C, Garrone C. Laparoscopic vs open hepatic resection: a comparative study. Surg Endosc 2003;17:1914-1918.

10. Singhal A, Huang Y, Kohli V. Laparoscopic liver resection for benign and malignant liver tumors. Hepatobiliary Pancreat Dis Int
2011;10:38-42.

11. Kaneko H, Takagi S, Shiba T. Laparoscopic partial hepatectomy and left lateral segmentectomy: technique and results of a clinical series. Surgery 1996;120:468-475.

12. Samama G, Chiche L, Bréfort JL, Le Roux Y. Laparoscopic anatomical hepatic resection. Report of four left lobectomies for solid tumors. Surg Endosc 1998;12:76-78.

13. Lee DS, Cui ML, Kim HJ, Yun SS. Gaining experience before establishing a totally laparoscopic left lateral sectionectomy as a standard procedure. Korean J Hepatobiliary Pancreat Surg 2010; 14:149-153.

14. Cheng KC, Yeung YP, Hui J, Ho KM, Yip AW. Multimedia manuscript: laparoscopic resection of hepatocellular carcinoma at segment 7: the posterior approach to anatomic resection. Surg Endosc 2011;25:3437.

15. Cherqui D. Laparoscopic liver resection. Br J Surg 2003;90:644646.

16. Buell JF, Thomas MJ, Doty TC, et al. An initial experience and evolution of laparoscopic hepatic resectional surgery. Surgery 2004;136:804-811.

17. Gagner M, Rogula T, Selzer D. Laparoscopic liver resection: benefits and controversies. Surg Clin North Am 2004;84:451-462.

18. Nguyen KT, Gamblin TC, Geller DA. World review of laparoscopic liver resection-2,804 patients. Ann Surg 2009;250:831841.

19. Bismuth H, Castaing D, Garden OJ. Major hepatic resection under total vascular exclusion. Ann Surg 1989;210:13-19.

20. Fabiani P, Katkhouda N, Iovine L, Mouiel J. Laparoscopic fenestration of biliary cysts. Surg Laparosc Endosc 1991;1:162-165.

21. Katkhouda N, Fabiani P, Benizri E, Mouiel J. Laser resection of a liver hydatid cyst under videolaparoscopy. Br J Surg 1992;79: 560-561.

22. Strong RW, Lynch SV, Wall DR, Ong TH. The safety of elective liver resection in a special unit. Aust N Z J Surg 1994;64: 530-534.

23. Gugenheim J, Mazza D, Katkhouda N, Goubaux B, Mouiel J. Laparoscopic resection of solid liver tumours. Br J Surg 1996;83: 334-335.

24. Clariá RS, Ardiles V, Palavecino ME, et al. Laparoscopic resection for liver tumors: initial experience in a single center. Surg Laparosc Endosc Percutan Tech 2009;19:388-391.

25. Zhang L, Chen YJ, Shang CZ, Zhang HW, Huang ZJ. Total laparoscopic liver resection in 78 patients. World $\mathrm{J}$ Gastroenterol 2009; 15:5727-5731.

26. Kazaryan AM, Pavlik Marangos I, Rosseland AR, et al. Laparoscopic liver resection for malignant and benign lesions: ten-year Norwegian single-center experience. Arch Surg 2010;145:34-40.

27. Nagorney DM, van Heerden JA, Ilstrup DM, Adson MA. Primary hepatic malignancy: surgical management and determinants of survival. Surgery 1989;106:740-748.

28. Makuuchi M, Takayama T, Gunvén P, Kosuge T, Yamazaki S, Hasegawa H. Restrictive versus liberal blood transfusion policy for hepatectomies in cirrhotic patients. World J Surg 1989;13: 644-648.

29. Cuschieri A, Shimi S, Banting S, Vander Velpen G. Endoscopic ultrasonic dissection for thoracoscopic and laparoscopic surgery. Surg Endosc 1993;7:197-199. 